Quaestio facti. Revista Internacional sobre Razonamiento Probatorio Quaestio facti. International Journal on Evidential Legal Reasoning Seccion: Ensayos N. 2 | 2021 pp. 155-184 Madrid, 2021

DOI: $10.33115 /$ udg_bib/qf.i2.22461 Marcial Pons Ediciones Jurídicas y Sociales (C) Diana Veleda ISSN: 2604-6202

Recibido: 16/06/2020 | Aceptado: 23/11/2020 | Publicado: 18/01/2021 Editado bajo licencia Reconocimiento 4.0 Internacional de Creative Commons

\title{
LA DECISIÓN SOBRE LA QUAESTIO FACTI EN LOS ACUERDOS DE CULPABILIDAD*
}

Diana Veleda

Universidad de Buenos Aires Universidad Torcuato Di Tella diana_veleda@hotmail.com

RESUMEN: La autora discute una posición relativamente extendida en el ámbito del Derecho Procesal Penal, según la cual la implementación de procedimientos de omisión del juicio penal o acuerdos de culpabilidad implica, necesariamente, la adopción de una noción de verdad distinta a la correspondencia con la realidad. Para ello, primero defiende la vigencia y la importancia de ese concepto de verdad en estos mecanismos y, luego, argumenta que existen razones morales, independientes a la búsqueda de la verdad, que justifican exigir a la fiscalía, a la hora de proponer un acuerdo de culpabilidad, que satisfaga el mismo estándar probatorio necesario para requerir la realización de un juicio ordinario. Finalmente, reflexiona sobre las implicancias que aquella exigencia, junto con otras características propias de este tipo de procedimientos, tienen en el mejoramiento de las condiciones epistémicas en las que tomamos la decisión sobre la quaestio facti en el contexto de los acuerdos de culpabilidad.

PALABRAS CLAVE: acuerdos de culpabilidad, verdad como correspondencia, verdad consensual, coerción, estándares probatorios.

\section{DECIDING ABOUT FACTS IN TRIAL AVOIDING MECHANISMS}

* Agradezco a Máximo Langer y Matías Díaz, por el acompañamiento y los consejos de siempre, y a Pablo Rovatti y Pablo Larsen, por su lectura y comentarios. 
ABSTRACT: The author challenges a doctrine that, to some extent, has been well accepted in the science of criminal procedure. According to such doctrine, the plea bargain and other mechanisms implemented to avoid trial embrace a concept of truth that is different from the concept upheld by correspondence theories. As opposed to such doctrine, the author reaffirms the validity and importance of a correspondence concept of truth in the context of the mechanisms to avoid trial. The author then suggests that there are moral reasons — not derived from the general interest in seeking the truth - that would require a prosecutor willing to propose a plea deal to have the same amount of evidence that would be necessary to move forward with a regular trial. The author ultimately envisage the consequences of applying the proposed standard, along with other specific characteristics of these proceedings, towards the enhancement of the epistemic conditions, under which we decide about facts in trial avoiding contexts.

KEYWORDS: trial avoiding mechanisms, correspondence theories, consensual theories, coercion, standards of proof.

SUMARIO: 1. INTRODUCCIÓN.- 2. LA VERDAD EN LOS ACUERDOS, ¿¿UNA PREOCUPACIÓN FUERA DE LUGAR?. 2.1. ¿Una verdad consensuada?. 2.2. Sobre la adecuación descriptiva de la noción de verdad consensuada en los acuerdos. 2.3. Sobre la adecuación normativa de la noción de verdad consensuada en los acuerdos.- 3. SOBRE LAS CONDICIONES DE LEGITIMIDAD MORAL DE LOS ACUERDOS DE CULPABILIDAD: LA MEDIDA DE LA PENA Y LA SUFICIENCIA DE LA PRUEBA. 3.1. ¿Propuestas o amenazas? Sobre la legitimidad de la propuesta de un acuerdo de culpabilidad por parte de la fiscalía. 3.2. La medida de la pena: recompensas vs. penalidades. 3.3. La suficiencia de la prueba: el estándar necesario para llevar el caso a un juicio ordinario.- 4. REPERCUSIONES EN LA DECISIÓN SOBRE LA QUAESTIO FACTI EN LOS ACUERDOS DE CULPABILIDAD. 4.1. Un determinado nivel de comprobación de la culpabilidad del acusado. 4.2. Un particular contexto de justificación: la inexistencia de hipótesis rivales propuestas por la defensa. 4.3. Una manifestación de conformidad, en principio, epistémicamente confiable.- 5. CONCLUSIONES.-6. BIBLIOGRAFÍA

RECOMMENDED CITATION: VELEDA, D., 2020: "La decisión sobre la quaestio facti en los acuerdos de culpabilidad», in Quaestio facti, 2: 155-184. Madrid: Marcial Pons Ediciones Jurídicas y Sociales. DOI: http://dx.doi.org/10.33115/udg_bib/qf.i2.22461

\section{INTRODUCCIÓN}

De un tiempo a esta parte, existe un consenso más o menos generalizado en el ámbito del derecho probatorio acerca de que la decisión sobre los hechos de un caso penal debe estar guiada por criterios de racionalidad epistemológica ${ }^{1}$. Es cierto que los juicios podrían terminar sin haber alcanzado la $v_{\text {erdad }}^{2}$, pero siempre es deseable

1 Muchas obras son representativas de esta corriente epistemológica en el derecho probatorio. Solo por mencionar algunas, véase TARUffo, 1992, Ferrer Beltrán, 2007 y 2005; GASCón Abellán, 20 io; Allen, 20io; Amaya, 20io y Laudan, 2006.

2 En razón de la vigencia del principio de inocencia y la intermediación de un estándar de prueba exigente para la comprobación de la culpabilidad, el proceso penal puede culminar normalmente aun- 
que sus resoluciones definitivas reflejen lo sucedido en el mundo real —esto es, principalmente, que condenemos a los culpables y absolvamos a los inocentes- ${ }^{3}$. Más aun, en el caso de las condenas, su legitimidad y la de sus consecuencias dependen de ello ${ }^{4}$. De allí que, dado que el criterio que utilizamos para justificar la veracidad o falsedad de enunciados los fácticos en un proceso penal es la prueba ${ }^{5}$, el sentido de las decisiones que lo componen y concluyen debería estar guiado por el grado de corroboración que la hipótesis acusatoria haya obtenido a partir de las evidencias recolectadas ${ }^{6}$.

Sin embargo, la gran mayoría de las legislaciones procesales penales del mundo permite emitir un pronunciamiento sobre la responsabilidad penal de una persona con prescindencia de la producción de la prueba en el debate y a partir de alguna clase de acuerdo entre la fiscalía y el acusado y su defensa ${ }^{7}$. Estos mecanismos se encuentran generalmente orientados hacia fines utilitarios - tales como la simplificación o abreviación de los procesos - ${ }^{8} \mathrm{y}$, al margen de su mayor o menor éxito en la consecución de esos objetivos ${ }^{9}$, suelen ser criticados por razones relacionadas con

que la hipótesis triunfante no sea la que goza de mayor apoyo empírico. Si la hipótesis de culpabilidad no alcanza el estándar necesario para la emisión de una condena, «se presumirá la verdad de la hipótesis menos confirmada (i.e., la de la inocencia)» (Ferrer Beltrán, 2010: 98).

3 Para Ferrer Beltrán, la investigación judicial pretende decir algo sobre el mundo y, por ello, intenta determinar el valor de verdad de determinadas premisas fácticas (2010: 81-84).

4 «En un sistema donde el Estado asume la función del control social por medio de la imposición de penas se encuentra, entre otras condiciones de legitimidad, la necesidad de que los elementos que permiten afirmar la existencia de un hecho punible estén verificados con certeza o probados más allá de la duda razonable. Como sucedáneo de esta regla, existe el deber del Estado y de sus representantes en el foro penal de investigar y determinar la verdad objetiva, y también, de pronunciarse a favor del acusado si no es alcanzada esta verdad más allá de la duda razonable. En otras palabras, existe la imposibilidad, desde un punto de vista normativo, de aplicar una pena sin tener acreditados con un determinado grado de precisión los hechos que habilitan tal potestad estatal» (DíAz, 2015: 103).

5 V., por todos, Ferrer Beltrán, 2010: 82-83 y, en el mismo sentido, 2005: 29-38.

${ }^{6}$ En este sentido, «la fijación judicial de los hechos debe recurrir necesariamente a los esquemas propios de la epistemología general» (GASCón ABELLÁn, 2010: 46) y «una hipótesis se considera verdadera (correspondiente con la realidad) cuando ha sido probada, y ha sido probada cuando, tras la valoración de la inferencia probatoria, alcanza un alto grado de credibilidad» y «los criterios de valoración de la prueba son paralelos a los criterios de confirmación de hipótesis propuestos por algunos filósofos de la ciencia» (González Lagier, 2003: 49).

7 En un reciente trabajo empírico, LANGer muestra que desde 1970 el plea bargaining y otros mecanismos de omisión del juicio penal fueron implementados, al menos, en sesenta jurisdicciones a lo largo del mundo (2019: 3-10).

8 Se ha argumentado también que esta clase de procedimientos pueden hallar sustento en razones no-utilitarias o de justicia, tales como la necesidad de mitigar el castigo a quien admite su culpabilidad (Duff, Farmer, Marshall y Tadros, 2007: 174).

9 No contamos con mucha información que permita juzgar concluyentemente si los procedimientos abreviados han colaborado con los fines que justificaron su implementación, pero los datos disponibles respecto del caso de la justicia nacional en la República Argentina no son alentadores. Un relevamiento estadístico determinó que «[e]n términos de la duración del proceso, el $20 \%$ de los procedimientos abreviados se resuelve en menos de dos meses y otro $20 \%$ entre 2 y 4 meses desde que el caso llega ante el tribunal oral. La mayoría de los caos (60\%) toman más de 4 meses y algunos hasta 1 
la justicia de las decisiones que de ellos resultan. En particular, se los critica porque facilitarían la punición de inocentes (FERRAJOLI, 1989: 748) e incitarían a la disminución de la pena justa de los autores culpables (SANCINETTI, 2010).

Con respecto a lo primero, los acuerdos facilitarían el castigo de inocentes, por un lado, porque serían procedimientos coercitivos ${ }^{10}$ que provocarían que los imputados decidan prestar conformidad con la propuesta de la fiscalía con el único fin de evitar posibles males mayores, tales como la aplicación de una sanción mucho más grave en el juicio ordinario ${ }^{11}$. En segundo lugar, porque al prescindir de la actividad probatoria dificultarían la posibilidad de detectar esas eventuales falsedades. De hecho, sin evidencia a la vista y si ello sirve a sus intereses, la fiscalía y el imputado podrían acordar la existencia de un evento - y, con ello, prescindir de probarlo-, cuando en rigor aquel no existe o no ha ocurrido de ese modo ${ }^{12}$.

Pese a todo esto, en muchas jurisdicciones, los acuerdos son la manera en la cual se procesa una gran parte de los casos que ingresan al sistema de justicia penal ${ }^{13}$. Una posible explicación de este fenómeno es que, en rigor, los acuerdos implicarían un abandono de la noción de verdad como correspondencia con la realidad y funcionarían a la luz de una noción de verdad consensual, según la cual la corrección de los enunciados fácticos no vendría determinada por su mayor o menor aproximación a lo ocurrido en el mundo, sino por la decisión misma de las partes de no controvertir los hechos del caso.

o 2 ańos desde que el caso llega ante el tribunal oral. El promedio de los casos que se resuelven por esta vía toman 301 días y la mediana es de 165 días desde que el caso llega ante el tribunal oral» (BerGMAN, FONDEVILA y LANGER, 2017: 62).

10 Solo por citar algunas opiniones en este sentido, para LANGBEIN, «[1] as semejanzas entre el sistema estadounidense moderno de plea bargaining y el antiguo sistema de tortura judicial son muchas y escalofriantes» (1978: 9) y para DíAz CANTón, «toda renuncia o conformidad [del acusado], para ser tal, precisa de la libertad total de decisión, inexistente por definición en [el] juicio abreviado", ya que «[e]s ilusorio pensar que la coerción puede ser eliminada del proceso, ya que la misma existencia del proceso la implica necesariamente» (2005: 252-253).

11 Aquí nos interesa especialmente esta consecuencia indeseable del presunto carácter coercitivo de los acuerdos, vinculada con el incremento del riesgo de error en la decisión sobre los hechos, pero esa condición es problemática en sí misma, en razón de la garantía que prohíbe al Estado obligar al imputado a realizar declaraciones contra sí mismo. Esto, claro está, siempre que se acepte que esta garantía no tiene un valor meramente instrumental o epistémico —es decir, orientado únicamente a prevenir declaraciones falsas - sino también un valor en sí misma.

12 De ahí que las implicancias del rol probatorio de las partes sea una de las peculiaridades que distingue al proceso judicial de otros contextos epistémicos (véase, en este sentido, Ferrer Beltrán, 2010: 90 y ss. y TARUfFo, 2010: 194-195). Por ello se considera importante que, en aquellos sistemas que priorizan el control de las partes sobre la investigación de los hechos, sean desarrollados incentivos apropiados para contrarrestar esa tendencia a incursionar en comportamientos distorsionadores de la verdad (DAMAšKa, 2003: 120)

13 LANGER analiza la relación existente entre el número de condenas obtenidas a través de mecanismos de evitación del juicio y el número total de condenas en veintiséis jurisdicciones del mundo y, en la mayoría de ellas, la tasa resultante excede el 50 por 100 de los casos (2019: 27 y ss.). 
En este trabajo sostendremos que, por el contrario, la resolución de casos penales a través de acuerdos de culpabilidad no nos compromete, necesariamente, con la adopción de una noción distinta a la de la verdad como correspondencia con la realidad. En particular, afirmaremos que los acuerdos deben observar determinadas exigencias independientes de la búsqueda de la verdad, vinculadas con su legitimidad moral —o, si se quiere, con el objetivo de evitar la violación de los derechos del acusado en ese contexto-, y que la observancia de esas exigencias repercute en las condiciones en las que adoptamos la decisión sobre la quaestio facti. Más precisamente, afirmaremos que aquellas facilitan que la decisión sobre los hechos goce de una genuina justificación epistémica, esto es, sobre la base de prueba y de acuerdo con un concepto de verdad como correspondencia con la realidad.

Para ello, descartaremos primero una objeción relacionada con la posible falta de coherencia interna de nuestra propuesta, según la cual, dado el origen y objetivos de los acuerdos, la preocupación por la averiguación de la verdad - entendida como correspondencia con la realidad- se encontraría fuera de lugar (punto 2). En segundo lugar sostendremos que, para que la propuesta de un acuerdo no sea coercitiva ni viole los derechos del acusado, la fiscalía no puede imponer a aquel una penalidad por elegir ir a un juicio ordinario y, además, debe contar con una sospecha suficiente en su contra, en particular, aquella que le permitiría solicitar la realización del debate público (punto 3). En tercer lugar, analizaremos la manera en la cual la observancia de esas condiciones de legitimidad moral de los acuerdos puede repercutir en la decisión sobre la quaestio facti (punto 4). Finalmente, ensayaremos unas breves conclusiones (punto 5).

\section{LA VERDAD EN LOS ACUERDOS, ¿UNA PREOCUPACIÓN FUERA DE LUGAR?}

\section{1. ¿Una verdad consensuada?}

El enfoque de este trabajo y su propuesta podrían merecer una objeción preliminar, relacionada con la aparente inconsistencia entre una preocupación fuerte por la averiguación de la verdad y la naturaleza y los objetivos de los acuerdos de culpabilidad.

Como ya adelantamos, estos procedimientos se apoyan en la ausencia de contradicción o en el consenso al que las partes arriban sobre ciertos aspectos del caso, con el fin de evitar la producción de prueba que estiman innecesaria, al manifestarse seguras sobre cuál sería su resultado. De hecho, la mayor parte de los sistemas que contienen la posibilidad de arribar a acuerdos fácticos en casos penales tienen su origen en el plea bargaining anglosajón y, allí, el reconocimiento de la culpabilidad por parte del acusado a través del guilty plea tiene una significación peculiar: constituye una auténtica cancelación de la controversia sobre los hechos y con ella —en princi- 
pio- deviene innecesaria la comprobación del contenido fáctico de la declaración ${ }^{14}$. Esto es connatural a un proceso concebido como adversarial, o bien como una disputa entre partes iguales que, además, son dueñas de la controversia que desarrollan (LANGer, 2005: 119) ${ }^{15}$, en el que el objetivo de la resolución de un conflicto prevalece, en términos generales, a la meta de la averiguación de la verdad (DAMAšKA, 1997: 120) ${ }^{16}$. De allí que se considere que la noción de verdad, en dicho contexto, resulte «más [relativa] y consensual: si las partes llegan a un consenso sobre los hechos del caso, mediante acuerdos sobre declaraciones de culpabilidad o estipulaciones, no es tan importante determinar cómo ocurrieron los hechos realmente» (LANGER, 2018: $39-40)$.

Estas particularidades de la decisión sobre los hechos en los acuerdos de culpabilidad podría explicarse, no tanto por la mayor o menor importancia que se confiere, en ese contexto, a la verdad como correspondencia con la realidad ${ }^{17}$, sino por la adopción, en su reemplazo, de un concepto de verdad diferente, de naturaleza con-

${ }_{14}$ Así, «analizado desde el modelo de la disputa [el guilty plea] cobra completo sentido», pues «si el proceso penal no es sino una contienda entre acusador y acusado, solo existe una controversia si este último se declara no culpable, mientras que si el imputado se declara culpable, ya no existe disputa alguna sobre la que el juez o el jurado puedan resolver, ya que el acusado se ha "allanado" a la pretensión del acusador, y entonces solo resta determinar la pena» (LANGER, 2005: 119).

15 El proceso penal estadounidense se acerca a lo que LANGER denomina como el modelo procesal de la disputa, en el que (i) el proceso penal es una lucha entre partes iguales —la fiscalía, por un lado, el imputado y su defensa, por el otro-, frente un tercero imparcial —el juez-; (ii) las partes son dueñas de la contienda, pues pueden disponer del contenido del litigio; (iii) en general, hay dos investigaciones paralelas que avanzan según el impulso que recibieren de cada parte y (iv) el objetivo del proceso es, al menos predominantemente, la resolución de un conflicto (LANGER, 2005: 114-123).

Es el dominio del caso en manos de las partes, como elemento característico de los modelos adversariales, lo que resulta central para este trabajo. Este elemento se encuentra presente en las diversas conceptualizaciones existentes sobre este tipo de modelo procesal. Puede leerse en DAMASKa (1997: 87 y siguientes) o en el adversarial legalism de Kagan. En efecto, este consiste en un método de contradicción legal entre disputantes que invocan intereses contrapuestos y que se caracteriza por el activismo de los litigantes. En sus palabras, se trata de «un estilo de contradicción jurídica en el que la afirmación de demandas, la búsqueda de argumentos legales dominantes y la recolección y presentación de evidencia están dominadas no por los jueces o por oficiales estatales, sino por las partes que disputan intereses contrapuestos, de manera tal que, a través del plea bargaining, el adversarial legalism «permite a las partes disputantes amenazar a sus adversarios con costos muy altos y demoras, lo cual alienta la resolución de los casos a través de negociaciones informales (y muchas veces extorsivas)» (2001: 9 y 84, mi traducción desde el original).

16 En efecto, «el omnipresente fin de la resolución del conflicto constituye un argumento silencioso a favor del mayor control de las partes sobre el desarrollo del proceso. No cabe duda, por ejemplo, de que la equiparación entre decisión judicial y resolución de conflictos favorece la idea de que solo los hechos controvertidos deben constituir el objeto de la actividad probatoria. Las admisiones de culpabilidad, en los procesos penales, y la admisión de hechos, en los civiles, se convirtieron con bastante naturalidad en parientes cercanos» (DAMAšKA, 1997: 120).

También se sostiene, sin embargo, que la opción entre la resolución de un conflicto y la averiguación de la verdad puede no ser siempre posible. Véase, por ejemplo, Weigend, 2003: 169.

17 Sobre el concepto de verdad como correspondencia con la realidad véase, por todos, Gascón Abellán, 2010: 51. 
sensual ${ }^{18}$, según el cual la solución del caso propuesta por las partes podría «apartarse de lo verdaderamente acontecido" (GUZMÁn, 2005: 297) ${ }^{19}$. De acuerdo con ello, los enunciados fácticos comprendidos en el acuerdo serían verdaderos porque las partes no los controvierten y no porque se haya corroborado que esa es la manera en la que los eventos se desarrollaron en el mundo a través de la evidencia recolectada u otro criterio de justificación disponible ${ }^{20}$. En este marco, una preocupación fuerte por la objetiva determinación de los hechos, en términos de correspondencia con la realidad, quedaría fuera de lugar. Discutiremos esta posición en lo que sigue.

\subsection{Sobre la adecuación descriptiva de la noción de verdad consensuada en los acuerdos}

Desde un punto de vista descriptivo, no es claro que los acuerdos de culpabilidad, sea cual fuere su origen, operen completamente divorciados de la noción de verdad como correspondencia con la realidad.

Esto es más evidente en los ordenamientos procesales de tradición europea-continental. Estos sistemas han incorporado los acuerdos de origen anglosajón pero los han traducido ${ }^{21}$ de acuerdo con las particularidades propias del modelo procesal

18 La idea de verdad consensual podría incluirse dentro de las teorías pragmatistas de la verdad, según las cuales "la verdad de un enunciado se concibe en términos de "aceptabilidad justificada". Un enunciado es verdadero si está justificado creer que es verdadero porque sirve a algún fin (versión "instrumentalista") o porque es aceptado (versión "consensualista"). En suma, un enunciado no está justificado porque sea verdadero, sino que es verdadero porque está justificado, o más exactamente, porque el criterio para aceptarlo como verdadero (el criterio de verificación) está justificado» (GASCón Abellán, 2010: 51).

19 En su análisis del caso del plea bargaining estadounidense, Bovino llega a una conclusión similar. Considera que, «al concederse a la declaración del imputado el mismo valor que al veredicto del jurado, la verdad se da por establecida. El consenso, en este contexto, desplaza, a la determinación judicial de la "verdad real"" (2005: 63).

20 Es necesario aclarar, sin embargo, que la distinción entre criterios y conceptos de verdad es confusa en las teorías pragmatistas de la verdad (GASCÓn ABELLÁn, 2010: 51) y que, de hecho, la distinción de las nociones de conceptos y criterios de verdad, en general, no es un asunto sencillo. Al respecto, puede consultarse HAACK, 1978: 88-91.

A los fines de este trabajo, nos bastará con afirmar que los acuerdos de culpabilidad no nos obligan a abandonar un concepto de verdad como correspondencia y reemplazarlo por un concepto consensual y que, en todo caso, según veremos más adelante, el consenso de las partes o la falta de contradicción de la hipótesis acusatoria podría ser uno de los factores contextuales que modifique las condiciones de justificación de la hipótesis acusatoria, a la luz de un concepto de verdad como correspondencia. En este sentido, el trabajo rechaza la adopción del consenso como concepto de verdad, en sentido extremo, pero no en un sentido moderado, como uno de los criterios de justificación de un enunciado con pretensión de verdad. Agradezco a Daniel González Lagier por esta precisión.

${ }^{21}$ Las ventajas de la metáfora de la traducción frente a la noción de los trasplantes legales puede leerse en LANGER, 2018: 67-76. 
subyacente $^{22}$. En estos contextos, la preocupación por la averiguación de la verdad conserva un lugar que no es para nada despreciable.

La confesión del acusado en un acuerdo de culpabilidad no es otra cosa que una fuente de conocimiento acerca de los hechos o, mejor dicho, una prueba más de su culpabilidad que, si no es corroborada con otros elementos que respalden su veracidad, podría ser insuficiente para el dictado de una condena ${ }^{23}$. De acuerdo con ello, «un acusado no puede poner fin a la etapa de la determinación de culpabilidad al admitir su responsabilidad ante el tribunal. Si bien la admisión de culpabilidad puede ser de mucha utilidad para el juez en la búsqueda de la verdad, lo cierto es que el juez todavía tiene la última palabra al respecto y en consecuencia puede decir: "le creo pero su confesión sola no es prueba suficiente más allá de toda duda razonable de que usted lo hizo"»(LANGER, 2018: 40-41) ${ }^{24}$.

Pero tampoco el plea bargaining anglosajón resigna toda preocupación por la objetiva determinación de los hechos. Por lo pronto, las Federal Rules of Criminal Procedure estadounidenses exigen que la declaración de culpabilidad cuente con una base fáctica suficiente y ponen en cabeza del tribunal la realización de las indagaciones necesarias para determinar su verificación en cada caso — regla 11.b.3 — ${ }^{25}$.

Es cierto que la noción de base fáctica suficiente parece haber sido dotada de un contenido bastante flexible en la jurisprudencia estadounidense. Una de las principales referencias a la que suele acudirse para argumentar que el plea bargaining descon-

22 Los sistemas procesales de origen europeo-continental se hallan tradicionalmente guiados por los principios de averiguación de la verdad, oficialidad y legalidad, generalmente asociados con una noción de disputa meramente formal entre las partes. A diferencia del caso estadounidense, estos procesos tienen más notas comunes con el modelo usualmente llamado inquisitivo o que LANGER denomina como de la investigación oficial, en el que (i) existe una única investigación; (ii) esta investigación es impulsada por un oficial del Estado; (iii) ese oficial no tiene un interés concreto en la resolución del litigio sino que actúa con objetividad, y (iv) las partes no pueden disponer materialmente del objeto del proceso (2005: 114-123).

${ }^{23}$ Como afirmamos en otra ocasión (VeLEDA, 2019: 280-281), la obtención de un reconocimiento de culpabilidad por parte del acusado también jugó un rol relevante en los procedimientos europeocontinentales, pero lo hizo de un modo bastante diferente al del modelo anglosajón, asociado a la práctica de la tortura y al sistema de pruebas legales (MaIER, 2004: 448 y FouCAUlT, 2014: 223-226).

24 Algunos ejemplos de esta clase de acuerdos, adaptados a la idiosincrasia de los procesos penales de tradición europea-continental, son el caso italiano (véanse, entre otros, LANGER, 2018: 93-103 y Maffei, 2004), el alemán (véanse, entre otros, Langer, 2018: 82-93, Dias, 2015 y Weigend, 2008) y el argentino (v., entre otros, LANGER, 2018: 103-108 y Córdoba, 2005: 229-250).

25 Regla 11.b.3.: "Determining the Factual Basis for a Plea. Before entering judgment on a guilty plea, the court must determine that there is a factual basis for the plea".

La correspondiente nota del Advisory Comitee agrega: "The court should satisfy itself, by inquiry of the defendant or the attorney for the government, or by examining the presentence report, or otherwise, that de conduct which the defendant admits constitutes the offense charged or an offense included therein to which de defendant has pleaded guilty. Such inquiry should, e.g., protect a defendant who is in the position of pleading voluntarily with an understanding of the nature of the charge but without realizing that his conduct does not actually fall within the charge". 
sidera la verdad como correspondencia es el precedente North Carolina v. Alford ${ }^{26}$. Allí, la Corte Suprema de los Estados Unidos resolvió que no presenta un problema desde una perspectiva constitucional la decisión de un tribunal de aceptar un guilty plea acompañado de una declaración de inocencia por parte del acusado. Aunque parece difícil conciliar esta posición con una pretensión dirigida a la objetiva determinación de los hechos, algunas reflexiones de la Corte Suprema de los Estados Unidos muestran que la preocupación por la precisión fáctica de la condena no se encontraba ausente. En particular, ese tribunal se dedicó especialmente a evaluar la trascendencia de la declaración de inocencia del acusado en función de la fortaleza del caso que la fiscalía tenía contra él. Al respecto, afirmó:

Aquí el Estado tenía un caso fuerte de homicidio en primer grado contra Alford. [...] En razón de la abrumadora evidencia en su contra, un juicio era precisamente lo que Alford ni su abogado deseaban. [...] Cuando su declaración de culpabilidad es vista a la luz de la evidencia que existía en su contra, la cual negaba, categóricamente, su proclamación de inocencia y le otorgaba al juez los medios para verificar si la declaración de culpabilidad estaba siendo efectuada de manera inteligente, su validez no puede ser cuestionada con seriedad (mi traducción desde el original).

De acuerdo con ello, aunque pensemos que la condena de Alford fue dictada en condiciones que están lejos de ser las ideales, no es adecuado afirmar que la decisión fue adoptada a la luz de una noción consensual de la verdad o con total despreocupación por la averiguación de lo realmente ocurrido. Las reiteradas referencias a la existencia de sólida evidencia sobre la culpabilidad del acusado muestran que la atención a lo realmente ocurrido está presente en el razonamiento de la Corte y que esto fue tenido en cuenta para restar credibilidad a la declaración de inocencia, todo ello a la luz de un concepto de verdad como correspondencia con la realidad.

También es cierto que existen otros factores, generalmente presentes en las formas robustas de plea bargaining, que pueden generar efectos distorsionadores de la verdad. Por ejemplo, en el caso estadounidense, la facultad que pueden tener los fiscales de imputar tipos penales adicionales a los que corresponderían al caso, la posibilidad de negociar la base fáctica de la acusación — fact bargaining - las dificultades que enfrentan los jueces para corregir esas desviaciones o la circunstancia de que los fiscales valoren más la resolución eficiente de los casos que la precisión de sus decisiones, al menos en aquellos procesos que involucran delitos leves (LIPpKE, 2011: 221-223). Sin embargo, esto tampoco nos obliga a abandonar nuestro punto.

Que los acuerdos celebrados en aquellos términos sean un mal camino para la determinación objetiva de lo ocurrido no es equivalente a afirmar que el sistema entienda que los hechos contenidos en ellos ocurrieron de ese modo simplemente porque las partes así lo afirman. En todo caso, las diferentes condiciones de celebración de estos procedimientos - p. ej., la mayor o menor presencia de esos factores distorsivos, la mayor o menor disponibilidad del objeto del caso en manos de la fiscalía y el acusado, la mayor o menor rigidez del control judicial sobre la satisfacción de la

26 "North Carolina v. Alford", 400 U.S. 25 (1970). 
base fáctica- mostrarán una correlativa preocupación, mayor o menor, por el conocimiento de lo realmente ocurrido. En otras palabras, los acuerdos no implican, necesariamente, la adopción de otra noción de verdad, pero sus características pueden reconocerle una importancia mayor o menor a su averiguación, en relación con los restantes valores en juego - p. ej., aquellos asociados a la eficiencia del sistema-. ${ }^{27}$

Una argumentación más o menos similar se utiliza para afirmar que la circunstancia de que un proceso sea considerado adversarial no basta para concluir que se encuentra guiado por un concepto distinto al de la verdad como correspondencia con la realidad o que no le interesa conocerla, en medida alguna. Para llegar a esas conclusiones, lo relevante es «si el ordenamiento exige efectivamente que la decisión se base en pruebas genuinas desde el punto de vista epistémico» y, en todo caso, «quedará por discutirse si la medida en que esa regulación propende a descubrir la verdad es o no satisfactoria, si se tutelan o no suficientemente otros valores, si se distribuye con justicia el riesgo de error, etc.; pero no cabrá decir que no le interesa la verdad sin más por el solo hecho de concebirse al proceso como adversarial» (DEI VeCCHI, 2016: 281). De manera similar, la sola posibilidad de resolver un caso penal a través de un acuerdo de culpabilidad no conlleva, necesariamente, la adopción de una noción de verdad consensual, sino que las particulares circunstancias en las cuales aquellos permitan adjudicar la solución del caso exhibirán el mayor o menor peso conferido al objetivo de arribar a decisiones precisas en el aspecto fáctico. Será fundamental, entonces, determinar si los acuerdos exigen que la decisión definitiva se base en "pruebas genuinas desde el punto de vista epistémico" y en qué medida.

\subsection{Sobre la adecuación normativa de la noción} de verdad consensuada en los acuerdos

Por último, desde una perspectiva normativa, no sería posible afirmar que los acuerdos de culpabilidad se fundan en una noción consensual de la verdad y que, con ella, pueden habilitar soluciones absolutamente ficcionales, sin cuestionar seriamente su legitimidad. La averiguación de la verdad, entendida como correspondencia con la realidad, es una condición de justicia de las decisiones resultantes de un proceso penal en un Estado de derecho ${ }^{28}$.

27 Existen muchos otros factores, además de los aquí enumerados, que pueden ser decisivos en el grado de autodeterminación del acusado a la hora de decidir declararse culpable y optar por una alternativa al juicio. Entre ellas, se encuentra la labor de los abogados defensores y su rol en el correcto asesoramiento del imputado acerca de la conveniencia de la herramienta en cada caso. Un análisis sobre la vigencia y el alcance del derecho a la asistencia técnica en el marco del plea bargaining estadounidense puede leerse en Petegorskr, 2013: 3631-3641. Agradezco a Carmen VÁzQuez por esta observación.

${ }^{28}$ Es cierto que la adecuación de la decisión sobre los hechos de un caso penal a lo realmente ocurrido puede no garantizar la justicia del resultado si, por ejemplo, la norma cuyo antecedente fáctico hemos corroborado es una norma injusta por otras razones - p. ej., fundada en prejuicios de clase, raza o religión-. La noción de justicia es utilizada aquí únicamente en ese primer sentido, relacionado con 
De acuerdo con el principio de verdad o de la verdad como garantía (Ferrajoli, 1989: 545), la corrección moral de una condena penal depende de la corrección fáctica del juicio de responsabilidad contenido en ella. En otras palabras, «la verdad, como correspondencia aproximada de una hipótesis con el objeto que refiere, constituye uno de los requisitos fundamentales que debe contener un sistema de persecución penal adecuado a un Estado de derecho, y respetuoso de la dignidad humana» y su búsqueda «debería aparecer como un objetivo relacionado con la pretensión de aplicar el poder punitivo en contra de una persona» o, más precisamente, "ante la intención de aplicar una pena estatal, debería surgir la obligación de determinar la verdad como garantía política del acusado», de manera que "el objetivo del proceso penal podría ser redefinido en términos de corroboración de la veracidad de la hipótesis acusatoria con pretensiones punitivas, en vez de búsqueda de la verdad en sí misma» (DíAz, 2017: 120-121).

Más allá del proceso penal, la verdad también funciona como un ideal regulativo general, pues el éxito del derecho como mecanismo ordenador de las conductas de las personas depende de la posibilidad de que las consecuencias establecidas en las normas jurídicas se apliquen, efectivamente, cuando ocurran los hechos a los cuales el derecho las condiciona. Así, «solo si el proceso judicial cumple la función de determinar la verdad de las proposiciones referidas a los hechos probados podrá el derecho tener éxito como mecanismo pensado para dirigir la conducta de sus destinatarios» (Ferrer Beltrán, 2007: 30) y, en conexión con ello, el principio también funciona como una condición necesaria de la legitimidad pública del sistema de justicia, pues si este fuera «frecuentemente percibido como uno que condena al inocente y que absuelve al culpable no conseguiría ganarse el respeto, ni la obediencia, de los gobernados» (LAUdAN, 2006: 23).

En definitiva, la verdad es un valor con múltiples repercusiones y la mayor o menor aptitud de un proceso penal para alcanzarla es un parámetro válido para analizar la justicia de las soluciones que produce, sea cual fuera la tradición jurídica de la que provenga ${ }^{29}$. Esto no significa desconocer la existencia de otros valores que también deben ser considerados y cuya mayor o menor incidencia se relacionará con las características de cada modelo procesal ${ }^{30}$. En todo caso, lo central es reflexionar sobre cuáles son las condiciones de celebración de los acuerdos que podrían reflejar una ponderación aceptable de todos los valores en juego.

la coincidencia entre la culpabilidad penal declarada en el juicio y los eventos ocurridos en el mundo real. Esto es, como ya dijimos, que condenemos a los culpables y absolvamos a los inocentes. Agradezco al Profesor Jordi Ferrer Beltrán por esta observación.

29 Esta posición implica, desde una perspectiva moral, considerar a la verdad como un valor universal. Sobre la dicotomía universalismo-relativismo moral puede consultarse Timmons, 2002: 38-41. Desde una perspectiva más cercana al relativismo, se considera que existen distintos tipos o nociones de verdad y justicia, dependiendo de la cultura procesal subyacente. Por ejemplo, véase Grande, 2008: $155-156$.

30 Véase, por todos, DAMAšKa, I997: I I 5-I 27. 


\section{SOBRE LAS CONDICIONES DE LEGITIMIDAD MORAL DE LOS ACUERDOS DE CULPABILIDAD: LA MEDIDA DE LA PENA Y LA SUFICIENCIA DE LA PRUEBA}

\section{1. ¿Propuestas o amenazas? Sobre la legitimidad} de la propuesta de un acuerdo de culpabilidad por parte de la fiscalía

En este apartado sostendremos que, para que la propuesta de un acuerdo de culpabilidad por parte de la fiscalía —o del órgano encargado de ello, según la legislación aplicable — no viole los derechos del acusado —o, según veremos, para que resulte moralmente aceptable-, deben verificarse, necesariamente ${ }^{31}$, dos condiciones: (i) que el acusado no sea amenazado con una pena exagerada si decidiera optar por la realización del debate ordinario y (ii) que la hipótesis acusatoria haya sido corroborada de conformidad con un estándar probatorio bien determinado, equivalente a aquel que resultaría exigible para llevar el caso a juicio. Estas exigencias se sustentan en razones independientes a una pretensión dirigida a la averiguación de la verdad, pero, como veremos más adelante, tienen implicancias concretas en el mejoramiento de las condiciones epistémicas en las cuales tomamos la decisión final. Veamos.

Una de las maneras más usuales de exhibir el carácter inmoral o coercitivo de los acuerdos es a través de su comparación con una escena compatible con lo que, normalmente, consideraríamos una amenaza. Tomemos, por ejemplo, el caso de una persona que es asaltada, a quien el ladrón exige que entregue sus pertenencias pues, si no lo hace, será asesinada o agredida de alguna manera. La posición del acusado frente a la propuesta de un acuerdo de culpabilidad sería asimilable a la del destinatario del asalto, porque también sería perjudicado si no procede como le piden. Es decir, si no renuncia a la realización del juicio, se enfrenta a la posibilidad de recibir una pena mayor. En ambos casos, el acusado y la víctima serían colocados frente a una opción injusta o meramente ficta, pues, en rigor, solo hay una respuesta racionalmente aceptable ante la alternativa propuesta, ya que, de otro modo, se verían colocados frente a una situación desventajosa - i.e., una pena más alta o algún riesgo para su vida o su salud, según el caso-. Como explica Kipnis:

Tanto el asaltante como el fiscal piden a las personas que realicen una elección difícil entre un perjuicio cierto y menor y un perjuicio incierto mayor. En la situación del asaltante, debo elegir entre la segura pérdida de dinero y la probabilidad difícilmente calculable de que el asaltante esté dispuesto y sea capaz de matarme si me resisto. Como imputado, me veo forzado a elegir entre un castigo cierto y menor y un castigo sustancialmente mayor con una probabilidad difícilmente calculable. Mientras la medida del perjuicio cierto disminuye y la magnitud de la

31 Es decir, se trata de condiciones necesarias, no suficientes. Existen otras razones por las cuales la propuesta de un acuerdo de culpabilidad por parte de la fiscalía podría violar los derechos del acusado, pero no todas ellas serán analizadas en este trabajo. La conclusión que se pretende alcanzar es que, ausentes las dos exigencias que sí se analizarán en este apartado, entonces la propuesta será ilegítima. 
probabilidad del perjuicio mayor aumenta, deviene más y más razonable elegir el primero (1976: 93-106, mi traducción desde el original).

La analogía, así formulada, ha sido criticada con buenas razones.

En primer lugar, existen diferentes clases de situaciones en las que nos enfrentamos a propuestas «que no podemos rechazar» o casos en los que, frente a una alternativa presentada por un tercero, existe una única opción racionalmente aceptable o debemos elegir "entre dos males»y, pese a ello, no consideramos que esa decisión haya sido el producto de alguna clase de coerción o de una situación de injusticia. LANGER ilustra esta situación con un ejemplo:

[S]i B tiene una enfermedad mortal y el médico A le propone someterlo a un tratamiento que, si B colabora, le salvará la vida pero lo dejará sometido a intensos dolores por el resto de su vida, entonces $\mathrm{B}$ debe elegir entre dos males: morir o colaborar con un tratamiento que lo llevará a sufrir intensos dolores por el resto de su vida. Si B optara por realizar el tratamiento, B podría decir que la propuesta de A era una 'propuesta que no podía rechazar', o que no tenía otra opción que la de aceptar la propuesta de A. Pero si B aceptara esa propuesta, normalmente no consideraríamos su aceptación como involuntaria. De este modo, si A le realiza el tratamiento a B, B no podría luego demandarlo por sus intensos dolores. En otras palabras, hay muchas situaciones en las que optar entre dos alternativas malas no constituye una decisión involuntaria. La diferencia entre la pena del juicio y la pena por declaración de culpabilidad tampoco convierte, por sí misma, la decisión de los acusados en involuntaria (LANGER, 2006: 232) ${ }^{32}$.

¿Qué distingue el caso de la víctima del asalto respecto del paciente médico? En ambos casos nos encontramos ante propuestas en las que un sujeto A propone a un sujeto $\mathrm{B}$ hacer la acción $\mathrm{X}$ y, además, anuncia que hará $\mathrm{Y}$ - perjudicial para $\mathrm{B}$ - si B no hace X (Wertheimer, 1979: 277). En nuestros ejemplos, esas propuestas serían «dame tu dinero y, si no lo haces, morirás», o «sométete a este tratamiento y, si no lo haces, morirás». Sin embargo, aunque asumamos que tanto la víctima del asalto como el paciente se encontraban, en alguna medida, compelidos a aceptar la propuesta del asaltante y del médico, respectivamente, nuestra intuición nos indica que, mientras la situación en la que fue colocada la víctima del asalto es injusta, la situación del paciente no lo es ${ }^{33}$.

32 La traducción al español, en cada cita de esta obra, corresponde a Agustín VArela y E. Matías Díaz, sobre «Repensando el Plea Bargaining: La Práctica y la Reforma del Juzgamiento por los Fiscales en el Proceso Penal Estadounidense», en Langer, Máximo, ¿Para qué sirve un modelo procesal? Ensayos sobre los sistemas acusatorio e inquisitivo, Marcial Pons, Madrid, en prensa.

33 El ejemplo podría criticarse porque el médico no es responsable por el riesgo de muerte al que se encuentra sometido el paciente, mientras que el asaltante sí lo es respecto de su víctima. Sin embargo, existen otros supuestos en los que el proponente no ha colocado a la víctima en la situación de desventaja que fundamenta la coerción desde una perspectiva psicológica, pero igualmente consideramos injusto su proceder. Imagínese que A cae a un precipicio accidentalmente y logra sostenerse, pero no podrá hacerlo por mucho tiempo. Entonces, B ofrece su ayuda a cambio de que A le entregue una suma de dinero. En este caso, B no colocó a A en una situación de desventaja pero sí se aprovechó injustamente de ella. En cualquier caso, al margen de la relevancia que, para la teoría moral sobre la coerción, pueda tener la circunstancia de que haya sido el proponente quien haya colocado al sujeto receptor en la disyuntiva en la cual se encuentra, los ejemplos todavía funcionan para comunicar la diferencia que 
A partir del concepto de coerción proporcionado por la ley contractual estadounidense $^{34}$, WERTHEIMER explica que, para afirmar que B fue objeto de coerción por parte de A para hacer X, debemos poder afirmar (i) que B fue psicológicamente compelido a aceptar hacer X y (ii) que debe resultar incorrecto para A compeler psicológicamente a $\mathrm{B}$ para que haga $\mathrm{X}$. Así, con respecto a la teoría moral subyacente a esas condiciones jurídicamente establecidas, Wertheimer sugiere que la coerción puede ser detectada a través de la realización de dos tests independientes: uno psicológico y otro moral (1979: 271).

Apliquemos los tests al caso de la víctima y del paciente. En primer lugar, tanto la víctima del asalto como el paciente se encontraron psicológicamente compelidos a aceptar las respectivas propuestas. Como vimos, ambos enfrentaron una oferta en la que solo una de las opciones disponibles era razonablemente aceptable, con la expectativa de evitar un mal futuro. En este específico sentido, ambas decisiones fueron el producto de una situación de coerción. Desde esta perspectiva psicológica, afirmar que la víctima y el paciente «involuntariamente aceptaron» la propuesta constituye un enunciado meramente descriptivo respecto del contexto de su decisión (WERTHEIMER, 1979: 209-210). Sin embargo, nuestra intuición moral ${ }^{35}$ nos sugiere que esas situaciones, aunque similares en el plano descriptivo, difieren sustancialmente en el plano normativo.

Según Wertheimer, la diferencia entre esas conductas puede advertirse si se indaga la legitimidad de lo que denomina el plan unilateral declarado por el proponente. Algunos planes de conducta conllevan la violación de un deber moral y, aunque la inmoralidad de un plan puede no ser una condición necesaria de la inmoralidad de una proposición bicondicional, sí es una condición suficiente (1979: 277) ${ }^{36}$. En el caso

luego estableceremos entre la situación del fiscal y el asaltante, esto es, la circunstancia de que la propuesta no constituya una violación de derechos, por subyacer a ella un plan de conducta inmoral o por reducir las opciones originalmente disponibles por parte del sujeto receptor. Agradezco al profesor Jordi FERRER BELTRÁn por esta observación.

34 En particular, The Restatement of Contracts, que define la coerción como «(a) cualquier acto injusto de una persona que compele una manifestación de aparente consentimiento de otra persona a una transacción determinada, sin su voluntad, o (b) cualquier amenaza injusta de una persona [...] que [induce] a otro a participar de una transacción bajo la influencia de dicho temor, desde que le impide ejercer su voluntad y su juicio» (WertheIMER, 1979: 271, mi traducción desde el original).

35 Una de las formas de evaluar críticamente una teoría moral es su atractivo intuitivo, es decir, su conformidad con nuestras creencias acerca de la moralidad de nuestras acciones (Timmons, 2002: 14).

36 Farrel y Spector entienden que la verificación de una situación de coerción depende del análisis de determinados factores, tales como la eliminación coactiva de una opción de la cual originalmente disponía el sujeto. En la amenaza, «una opción disponible para el agente antes de la propuesta resulta eliminada una vez hecha ésta; en la propuesta, en cambio, se mantiene la opción original y se agrega por lo menos una nueva opción» (1992: 20). Sin embargo, la moralidad de la propuesta no es determinante, a su juicio, para afirmar la existencia de un caso de amenaza y podríamos encontrarnos ante una escena que no involucre una amenaza sino una oferta, pero que esta resulte inmoral (1992: 23-30). La distinción no afecta nuestro argumento. La fiscalía no debe amenazar al acusado pero tampoco puede realizar una oferta inmoral, en violación a los derechos que aquel tiene en el contexto de esa decisión. 
del médico, su plan unilateral —realizar un tratamiento doloroso para tratar la enfermedad del paciente- no constituye la violación de ningún deber moral a su cargo, pero sí lo es el plan declarado por el ladrón — apropiarse del dinero de la víctima-. Esto quiere decir que, mientras que el médico tenía el derecho de someter al paciente a esa alternativa, el ladrón violó un deber moral al someter a la víctima de esa manera.

¿Qué sucede, entonces, con la propuesta de un acuerdo de culpabilidad formulada por la fiscalía? Según el enfoque que elegimos, es necesario analizar si la fiscalía, al proponer un acuerdo de culpabilidad, declara un plan unilateral legítimo o, por el contrario, viola los derechos del acusado ${ }^{37}$.

Para ello, primero debemos dilucidar cuál es el plan unilateral declarado por la fiscalía. Al proponer un acuerdo, la fiscalía ofrece, en principio, la imposición de una pena reducida a cambio de la declaración de culpabilidad del acusado. Como contrapartida - es decir, para el caso en el que el imputado no acepte su ofrecimiento- la intención declarada por la fiscalía es la de promover la realización de un juicio ordinario y solicitar allí la imposición de una pena mayor. En consecuencia, el ofrecimiento de la fiscalía es una propuesta estructurada, a grandes rasgos, de la siguiente manera: «La fiscalía propone la pena $\mathrm{X}$ al imputado a cambio de que admita su culpabilidad y, si el imputado no acepta ese acuerdo, declara que solicitará la realización del juicio y la imposición de una pena mayor».

La moralidad de ese plan unilateral depende, entonces, de que la fiscalía no viole ningún derecho del acusado al solicitar la realización de un juicio y la imposición, en ese contexto, de una pena mayor. Para conocer si ello es así, es necesario determinar cuáles son las condiciones en las que, legítimamente, la fiscalía podría promover esas demandas.

\subsection{La medida de la pena: recompensas vs. penalidades}

Revisemos, en primer lugar, la cuestión vinculada con la pena en expectativa. Como vimos, la circunstancia de que el acusado espere una sanción mayor en el eventual juicio significa, para algunos, que su decisión de renunciar a ese derecho nunca será libre, ya que la intención de evitar un castigo mayor funcionará como un

37 LANGER se refiere a este asunto a través de la noción de base moral — moral baseline - de los acuerdos, es decir, a qué tiene derecho moralmente el acusado frente a la propuesta de la fiscalía. Según explica, la base moral de los acuerdos de culpabilidad está compuesta por tres elementos. Primero, el fiscal «no debería efectuar propuestas de declaración de culpabilidad en los casos en los que un jurado razonable no podría encontrar al acusado culpable más allá de una duda razonable», segundo, "los acusados [también] tienen derecho a esperar que, si son condenados en un juicio, el sistema de justicia penal aplicará una pena justa adecuada a las características del delito y del condenado» $\mathrm{y}$ "[f]inalmente, como oficiales de justicia que son, los fiscales deben imputar a un individuo solo por delitos que describan adecuadamente la conducta realizada por él, [...] que no sea socialmente inocua» (2006: 236-240). 
incentivo para prestar conformidad con el acuerdo, incluso si ello implica emitir una confesión total o parcialmente falsa.

Es necesario distinguir dos escenarios posibles. Imaginemos el caso en el que A es acusado por el delito de robo, que tiene una pena de un mes hasta seis años de prisión. Imaginemos también que, en razón de las circunstancias del hecho - y los restantes datos que el sistema considere relevantes para evaluar este punto-, la pena estimable para A sería de cuatro años de prisión. En este supuesto, la concreción de un acuerdo por dos años de prisión contendría una reducción de dos años respecto de aquella sanción que, por razones de justicia, sería esperable para A. En otras palabras, A resultaría beneficiado o recompensado por su decisión de evitar la realización del juicio. Sin embargo, si A fuese además amenazado con que, en caso de no aceptar el acuerdo, será solicitada en el juicio una pena de seis años de prisión, entonces la propuesta de la fiscalía también contendría una especie de penalidad por la decisión de rechazar el acuerdo, esto es, un incremento de dos años en la sanción normalmente esperable en ese caso.

Recapitulando, al celebrar un acuerdo de culpabilidad, un acusado puede ser beneficiado con la reducción de la pena en expectativa, pero también puede ser amenazado con ser castigado por hacer uso de su derecho a ir a un juicio ordinario. En el primer caso, nos hallamos ante la concesión de una recompensa por la renuncia al juicio - waiver reward - $\mathrm{y}$, en el segundo, ante la imposición de una penalización por la elección del juicio — trial penalty - (LippKe, 2011: 10-23) ${ }^{38}$.

Ahora bien, a diferencia de la concesión de una recompensa, la imposición de una penalización es una conducta moralmente reprobable porque «los acusados tienen derecho a esperar que, si son condenados en un juicio, el sistema penal de justicia aplicará una pena justa adecuada a las características del delito y del condenado» (LANGer, 2006: 239). Entonces, si la propuesta de la fiscalía incluye esa clase de penalización, su plan unilateral declarado no es legítimo, mientras que si contiene una recompensa, sí lo es ${ }^{39}$.

El respeto de esta condición también permite descartar que el ofrecimiento de la fiscalía constituya una amenaza, entendida como la eliminación coactiva de una

38 La posibilidad de practicar esta distinción depende, claro, de la existencia de un procedimiento confiable para la determinación de la sanción esperable tras la celebración ordinaria del debate. Podría tratarse, por ejemplo, de la realización de una audiencia ante el tribunal en la que se establezca la sanción justa en expectativa, de acuerdo con las circunstancias del caso, junto con la obligación de respetarla como tope máximo en el eventual debate público (Lippke, 2011: 16-23).

39 No pretenden aquí descartarse todas las objeciones que podrían dirigirse contra la práctica de disminuir la sanción esperable en razón de la celebración de un acuerdo. Como vimos, los acuerdos de culpabilidad también son criticados, desde un punto de vista moral, en razón de la reducción de la pena justa dirigida a los autores culpables (SANCINETTI, 2010). El único punto que pretendemos alcanzar es que, mientras la fiscalía ofrezca una recompensa por la omisión del juicio - waiver reward-y no una penalización por la elección del juicio — trial penalty—, no podría afirmarse que la «amenaza» de la imposición de esa pena es injusta, puesto que se trata de aquella sanción que sería normalmente esperable a la luz de los parámetros que la legislación establece para su determinación. 
opción originalmente disponible para el receptor de la propuesta (FARREL y SPECTOR, I 992: 20). Volvamos al caso del asaltante. Es claro que el «ofrecimiento» del asaltante constituye una amenaza porque la víctima pierde injustamente una opción disponible antes de la realización de la propuesta: conservar sus pertenencias y no ser agredida en su vida o su salud. ¿Qué sucede en el caso del acusado? Si la fiscalía propone un acuerdo de culpabilidad, pero amenaza con solicitar la imposición de una pena excesiva en un eventual juicio, podríamos afirmar que, en alguna medida, elimina una opción originalmente disponible para el acusado, es decir, la de participar del juicio y obtener allí una pena justa. En cambio, si la fiscalía propone una recompensa por la evitación del juicio — waiver reward —, el acusado gana una nueva opción —la de realizar el acuerdo y obtener una sanción disminuida-, pero no pierde las alternativas originalmente disponibles — acudir al juicio y obtener una sanción justa-

\subsection{La suficiencia de la prueba: el estándar necesario para llevar el caso a un juicio ordinario}

Nos queda analizar bajo qué condiciones la fiscalía tiene el derecho de solicitar la realización de un juicio respecto del acusado. Una de las condiciones necesarias, aunque no suficientes, de dicha potestad, es que la fiscalía cuente con una determinada sospecha dirigida al imputado, fundada en suficiente evidencia obtenida durante la investigación preliminar que determine la probable existencia del hecho y su participación en él.

Esto se explica, en buena medida, porque la intervención del acusado en el juicio público, además de ser su derecho, es una de las cargas que le resultan exigibles en razón de su sometimiento a un proceso penal. El Estado tiene la potestad de requerir su presencia allí y, de hecho, en la mayor parte de las legislaciones procesales penales del mundo, tiene la facultad de compelerlo a presentarse a través de la fuerza pública. Esta carga supone, claro, la restricción de otros derechos y libertades ${ }^{40}$, de manera que debe ser exigida razonablemente, es decir, cuando el Estado cuente con elementos suficientes para justificar esa decisión ${ }^{41}$.

40 Para PAstor, «la persecución penal implica, desde el comienzo, el sometimiento del imputado a condiciones de semi-penalización que se manifiestan en ciertos padecimientos que encuadran en el llamado carácter idéntico a la pena que se atribuye ya al proceso penal: angustia, gastos, pérdida de tiempo y de trabajo, humillación, descrédito, etc.» (2009: 393).

41 En su análisis del caso estadounidense, LANGER agrega que, dado que el fiscal tiene el deber de buscar justicia, «no debería efectuar propuestas de declaración de culpabilidad en los casos en los que un jurado razonable no podría encontrar al acusado culpable más allá de una duda razonable», entonces, «si un fiscal no tiene, como mínimo, evidencia suficiente para sortear o pasar el umbral de una decisión absolutoria directa por parte del juez luego de que la fiscalía presentó su caso en juicio y antes de que la defensa presente su caso, el fiscal tiene el deber moral de no incitar al acusado a declararse culpable mediante una propuesta de declaración de culpabilidad» (2006: 236-237). 
En definitiva, si el plan unilateral declarado por la fiscalía es la realización de un debate oral y público, la moralidad de esa pretensión dependerá de la observancia de la totalidad de las condiciones necesarias para llevarla adelante legítimamente. Entre ellas, se encuentra la existencia de una cantidad de prueba que sustente la hipótesis acusatoria con un grado de probabilidad determinado, según el cual resulte normalmente tolerable la carga exigible a todo acusado de someterse a un enjuiciamiento penal. De acuerdo con ello, la propuesta de un acuerdo de culpabilidad debe apoyarse en la satisfacción del mismo estándar de prueba aplicable a la decisión de remitir un caso penal a un juicio ordinario.

\section{REPERCUSIONES EN LA DECISIÓN SOBRE LA QUAESTIO FACTI EN LOS ACUERDOS DE CULPABILIDAD}

Como vimos antes, las condiciones de legitimidad de los acuerdos — relacionadas con la suficiencia de la prueba sobre la culpabilidad y la medida de la pena- tienen una justificación moral lógicamente independiente de una pretensión específicamente orientada a la averiguación de la verdad. Sin embargo, si las observamos debidamente, contribuirán al mejoramiento de la precisión fáctica de las decisiones resultantes de los acuerdos.

En otras palabras, las exigencias antes descriptas, que los acuerdos deben necesariamente observar para no violar los derechos del acusado, repercuten en las condiciones en las cuales tomamos la decisión sobre la quaestio facti en estos contextos y permiten afirmar que la condena resultante de los acuerdos podría gozar de una justificación genuina desde un punto de vista epistémico, esto es, sobre la base de prueba y de acuerdo con una noción de verdad como correspondencia con la realidad.

Para ello, contaremos con (i) un determinado nivel de comprobación de la culpabilidad del acusado, a través de las evidencias recolectadas durante la investigación preliminar, (ii) la inexistencia de hipótesis rivales a la acusatoria y la expresa aceptación de ésta por parte del acusado y (iii) una manifestación de conformidad que, en principio, es epistémicamente confiable.

\subsection{Un determinado nivel de comprobación de la culpabilidad del acusado}

Según vimos, para proponer un acuerdo de culpabilidad, la fiscalía debe haber satisfecho un estándar probatorio asimilable al que resultaría exigible para llevar el caso a juicio.

La intermediación de un estándar de prueba implica que el juzgador sobre los hechos deberá determinar si las evidencias proporcionan a la tesis de la acusación 
un grado de corroboración suficiente para aceptarla. Efectivamente, un estándar de prueba «especifica el umbral mínimo que ha de ser satisfecho a los efectos de aseverar que una hipótesis ha sido probada» (LAUDAN, 2006: 104), de manera que, al adoptar una decisión sobre los hechos probados ${ }^{42}$, el juzgador deberá dilucidar si la hipótesis puede considerarse comprobada con el grado de confirmación de que se disponga (Ferrer Beltrán, 2007: 47; HaAcK, 2013: 75).

Es generalmente aceptado que en el proceso penal existen diferentes clases de estándares, según cuán exigentes sean con respecto al grado de acreditación que debe haber alcanzado la hipótesis para poder ser aceptada ${ }^{43}$. La existencia de un estándar de prueba supone también una determinada distribución del riesgo de error en la decisión asociada con él (Ferrer Beltrán, 2018: 406 y 425). En particular, una de las razones que puede justificar una determinada distribución del riesgo de error a través de un estándar más o menos exigente viene dada la diferente gravedad de las equivocaciones posibles (idem: 409-410). Por ejemplo, en el caso de la decisión definitiva en un caso penal, el costo de las condenas erróneas y de las absoluciones erróneas ${ }^{44}$.

¿Cuán costosos son los falsos positivos y los falsos negativos en la resolución que discutimos? Aquí se impone una aclaración. La decisión sobre la legitimidad de la propuesta de la fiscalía no es, estrictamente, una decisión sobre una cuestión fáctica o que, al menos de manera directa, esté sometida a un estándar de prueba determinado. Son las exigencias morales a las que se encuentra condicionado el ofrecimiento de la fiscalía las que, según vimos, obligarían al juzgador sobre los hechos a determinar si la hipótesis acusatoria goza del grado de corroboración que hubiera sido necesario para la adopción de un pronunciamiento distinto, esto es, el de llevar el caso a juicio. Entonces, lo que el tribunal debe indagar es si fue satisfecho el estándar probatorio asociado con esa otra resolución, pues existen razones morales para conectarla con la determinación de proponer un acuerdo de culpabilidad. Así, la definición del estándar de prueba y la consecuente distribución del riesgo de error serán aquellas correspondientes a la decisión de llevar un caso a juicio.

Entre los costos que pueden ser evaluados para determinar la gravedad del error en la decisión de llevar un caso a juicio o, como contrapartida, en la decisión de no celebrarlo, se encuentran las restricciones a los derechos y libertades del acusado que representa la realización de ese acto, por un lado, y los costos asociados a la decisión

42 Ferrer Beltrán, 2007: 41 y ss.

43 Efectivamente, "“[e]n cada punto del procedimiento [penal] en que a un juez o a un jurado le corresponde hacer una determinación de derecho o una relativa a los hechos del caso, hay un EdP [—estándar de prueba—] asociado a esa decisión» y, cuando se emplean estándares de prueba, «subyace implícitamente la expresión de los costos relativos a los éxitos y los errores que pueden derivarse de la decisión respectiva» (LAUdAn, 2006: 133-134).

44 Por ejemplo, una determinada posición sobre los costos relativos a las decisiones definitivas de un proceso - es decir, a la dicotomía condena-absolución- puede verse en LAUDAN, 2006: 111 y ss. 
de clausurar anticipadamente una investigación, por el otro ${ }^{45}$. En ambos casos, los errores son de menor gravedad en comparación con aquellos asociados al pronunciamiento final. Someter a una persona a juicio injustamente no es igualmente grave que condenarla injustamente y decidir no promover un debate tampoco es igualmente grave que absolver injustamente a alguien, máxime cuando ese pronunciamiento es generalmente provisional y no impide reeditar la pretensión de realizar el juicio en un futuro.

En ese contexto, usualmente se considera que la elevación de un caso a juicio se encuentra condicionada a la recolección de evidencia que haga presumir como probable que podría condenarse al acusado de conformidad con el estándar aplicable a la decisión final ${ }^{46}$. Para solicitar la realización de un juicio «no se le requiere al acusador que demuestre con certeza la culpabilidad del acusado", sino que «[b]astará aquí que demuestre la probabilidad de que la persona sometida a proceso haya cometido el hecho", noción que, «en punto al requisito cognoscitivo, [tiene] cierta similitud con el estándar probatorio de la preponderancia de la prueba» (Limardo, 2018: 99) ${ }^{47}$, según el cual cabe elegir el «enunciado que parezca relativamente "más probable", sobre la base de los medios de prueba disponibles" (TARUfFo, 2008: 137-138), o bien con la idea de la probabilidad prevaleciente como criterio de selección entre hipótesis contradictorias o incompatibles, según la cual resulta aceptable seleccionar aquella que «reciba el apoyo relativamente mayor sobre la base de los elementos de prueba conjuntamente disponibles» (TARUfFo, 2011: 299).

La elección de esas categorías u otras no es aquí decisiva ${ }^{48}$, aunque sí es deseable transmitir al juzgador sobre los hechos los parámetros propios de una decisión

45 La idea de que la decisión de llevar un caso a juicio no debe ser adoptada arbitrariamente, en razón de los padecimientos que ello implica para el sujeto acusado, puede leerse en MaIER, 2004: 362, Bertelotti, 2009: 103-122, entre muchos otros. También se ha sostenido que la necesidad de que la decisión de llevar un caso a juicio se encuentre debidamente fundada responde a la necesidad de evitar, en la mayor medida posible, absoluciones incorrectas con fuerza de cosa juzgada (Deu, 2007: 48).

46 Por ejemplo, para Cafferata Nores la elevación a juicio «requerirá probabilidad» (2008: 11-12) y para MAIER, la apertura a juicio debe producirse cuando «aparezca como probable una condena, esto es, cuando exista la probabilidad acerca de la existencia de los elementos de la imputación deducida en la acusación que, eventualmente, permitan condenar al tribunal de juicio» (2011:358-359).

47 El autor propone, sin embargo, que para evitar la realización de un pre-juicio para decidir sobre la necesidad del juicio ordinario, el control del mérito de la acusación durante la etapa intermedia debiera consistir en un "control negativo de arbitrariedad, en donde la tarea del juez que lo efectúa se concentra en corroborar que no exista arbitrariedad, por lo que solo en los casos en que resulte evidente que la base probatoria de la acusación es insuficiente para alcanzar el estándar cognoscitivo requerido y, en esa medida, arbitraria, deberá proceder a cumplir con su función de filtro e impedir que esa acusación prosiga» (Limardo, 2018: 122-123).

${ }_{48}$ No es claro que lo ideal sea tener definiciones precisas de los estándares, aunque ello sea posible (v. HAACK, 2013: 70 y siguientes) y la posibilidad misma de formular un estándar preciso, que funcione como umbral en la decisión sobre los hechos probados, ha sido controvertida. A favor de esta posibilidad, véase Ferrer Beltrán, 2018: 405-419 y 2007: 139 y siguientes y, en contra de esa posibilidad, véase GonZÁlez LAGIER, inédito. 
intermedia, necesarios para determinar el nivel de evidencia exigible, en términos relativos ${ }^{49}$. En este caso, el grado de corroboración de la hipótesis acusatoria debe ser menor a aquel exigible para la adopción de la condena, pero mayor a aquel aplicable a las decisiones iniciales del proceso — por ejemplo, la de comenzar una investigación o poner en conocimiento del acusado los hechos que se le imputan-.

Podría objetarse que las evidencias reunidas durante la investigación preliminar son de baja calidad, pues son recolectadas unilateralmente por las policías o las fiscalías y no son sometidas al control propio del debate ${ }^{50}$, y que, en esas condiciones, la hipótesis acusatoria, aunque carente de rivales, puede no ser otra cosa que una «mala explicación». Efectivamente, si entendemos la decisión sobre los hechos probados como una inferencia a la mejor explicación, consistente en un proceso de maximización de la coherencia, la elaboración de una base de coherencia pobre puede provocar que la explicación finalmente escogida sea la mejor entre aquellas disponibles, pero una mala explicación al fin de cuentas (AмAYA, 2013: 19-20).

Ahora bien, ese riesgo podría ser compensado si la observancia de ese estándar es sometida a un control intersubjetivo fuerte y si, en ese control, se contempla la noción de completitud del cuadro probatorio.

Respecto de lo primero, es claro que el acusado y su defensa deben ser puestos en conocimiento de la totalidad de la evidencia reunida por la fiscalía en su contra. De esa manera, podrán controlar esa prueba y, en su caso, proponer las hipótesis alternativas que consideren necesarias. Efectivamente, «[l]a omisión de revelar la prueba favorable a la defensa interfiere con un mecanismo central para controlar que los fiscales no efectúen propuestas de acuerdo en casos débiles» (LANGER, 2006: 272) ${ }^{51}$. Volveremos a referirnos a este punto en el siguiente apartado.

49 Como explica González Lagier, "[t] odo el mundo entiende que el criterio de confirmación 'más allá de toda duda razonable' es más exigente que el de la "prueba preponderante" o el de "prueba clara y convincente" [...]. Al menos, los estándares deberían transmitir la información de si la autoridad jurídica quiere establecer un nivel de exigencia mayor o menor, aunque no logren precisar cuál y, por tanto, si se ha alcanzado suficiente prueba acabe dependiendo de la estimación del juez y su buen criterio" (inédito).

50 Para Langer, el elemento común entre las diferentes adaptaciones de los procedimientos de omisión del juicio implementados a lo largo del mundo es la administratización del proceso. Según explica, «las condenas basadas en el consentimiento del acusado y en la evidencia recolectada en procedimientos administrativos le otorga mayor poder a la policía, a otras agencias administrativas y a la fiscalía, quienes los desarrollan en la medida en que no son cuestionados ni responsabilizados a través de un juicio y dado que sus decisiones de detener e imputar a un individuo por un determinado delito pueden no ser accesibles o transparentes para terceros, los ciudadanos o los medios de comunicación» (2019: 25).

51 En el ámbito estadounidense, ha sido discutida la vigencia y, también, la suficiencia de la regla de disclosure establecida en el precedente Brady v. Maryland, 373 U.S. 83, 86 (1963), en el ámbito del plea bargaining. De acuerdo con esa regla, se considera una violación al debido proceso, fundada en las enmiendas quinta y catorceava de la Constitución de los Estados Unidos, que la fiscalía no revele prueba de descargo que es decisiva para la decisión sobre la culpabilidad o la pena. Una argumentación en favor de la vigencia de dicha regla en el ámbito del plea bargaining, sobre la base de fundamentos diversos 
En segundo lugar, al margen del conocimiento e intervención del propio acusado y su defensa, es central el control por parte del tribunal sobre la observancia del estándar necesario para proponer el acuerdo y, en el ejercicio de ese control, podría resultar útil la idea del peso de la prueba o de la completitud del cuadro probatorio $^{52}$. Esta noción «mide al grado de completitud (i.e., la riqueza) del conjunto de elementos de juicio con el que se adopta la decisión", es decir que, "mientras que el valor probatorio de una hipótesis da cuenta de la probabilidad de que esa hipótesis sea verdadera en términos comparativos con sus hipótesis rivales, el peso probatorio da cuenta de la probabilidad de acierto de la decisión, en función de la riqueza de los elementos de juicio tomados en consideración para decidir», de modo tal que, «incorporando el requisito de la completitud del peso probatorio ya no se produciría la consecuencia de tener que declarar probada una hipótesis con muy escaso apoyo probatorio, únicamente por ser relativamente mejor que su contraria» (Ferrer BeLTRÁN: 418, nota 31).

En consecuencia, si el tribunal que controla la satisfacción del estándar necesario para llevar el caso a juicio — al analizar la legitimidad de la propuesta del acuerdoincluyera la dimensión del peso o de la completitud del cuadro probatorio, podría evitarse, en buena medida, el problema asociado a la posibilidad de que la hipótesis seleccionada sea, en rigor, una «mala explicación» ${ }^{53}$.

\subsection{Un particular contexto de justificación:}

la inexistencia de hipótesis rivales propuestas por la defensa

Al margen del estándar probatorio necesario para proponer el acuerdo — que, como ya vimos, es equivalente a aquel exigible para llevar un caso a juicio-, estos procedimientos cuentan también con una declaración a través de la cual el acusado no controvierte que los hechos se desarrollaron de conformidad con el relato contenido en la hipótesis de la fiscalía ${ }^{54}$. Entonces, en el contexto epistémico final, en el

- desde la teoría unconstitucional conditions, hasta las reglas de los contratos, el derecho de propiedad y el debido proceso legal- puede leerse en BLANK, 2000: 2060-2085. Una argumentación en torno a la posible insuficiencia de la revelación según "Brady" para el caso de los acuerdos de culpabilidad, puede verse en Douglass, 2001.

52 HAACK se refiere a este punto como la completitud del cuadro probatorio — comprehensiveness(2014: 60, 218, entre otras).

53 Podría seleccionarse, para el caso, alguno de los estándares intermedios propuestos por Ferrer Beltrán en su catálogo, que incorporan la dimensión del peso probatorio. Por ejemplo, aquel según el cual «[u]na hipótesis sobre los hechos se considerará probada cuando se den, conjuntamente, las siguientes dos condiciones: a) Que la hipótesis ofrezca una mejor explicación de los hechos cuya ocurrencia se trata de probar que la hipótesis de la parte contraria, a la luz de los elementos de juicio existentes en el expediente judicial; y b) Que el peso probatorio del conjunto de elementos de juicio relevantes incorporados al proceso sea completo (excluidas las pruebas redundantes)» (2018: 418).

54 Esto es así, claro está, en los acuerdos en los cuales la conformidad del acusado implica la aceptación de los hechos y de su participación en estos. El análisis que efectuamos en este punto no es aplicable 
que adoptamos la decisión conclusiva para el caso, nos encontramos no solo con que el acusado no ha propuesto una hipótesis rival a la acusatoria, sino con que la acepta expresamente.

Existen diferentes teorías que explican el mecanismo de adopción de decisiones sobre los hechos en casos penales como un proceso de selección entre hipótesis alternativas, según su capacidad explicativa respecto de la evidencia disponible.

Por ejemplo, para Allen, la decisión sobre la responsabilidad penal del acusado consiste en la selección de una versión plausible de la culpabilidad y, además, en la inexistencia de una versión plausible de su inocencia (2010: 123). En particular, en un juicio penal, "[l] as partes tratan de exhibir las debilidades de los argumentos de sus oponentes pero, principalmente, intentan mostrar que su propia versión de la realidad es verdadera" y "la funcionalidad de la prueba en los procesos judiciales opera comparativamente respecto de las versiones de los hechos presentadas por las partes» (Ibid.: 134-135). Si aceptamos que esta es la manera en la cual decidimos sobre los hechos en un caso penal, es razonable prever que, frente a la aceptación expresa por parte del acusado de la hipótesis formulada por la acusación, esta se presente como la explicación más plausible acerca de lo ocurrido.

Desde esta perspectiva, la justificación es sensible al contexto y el grado de corroboración que exigimos para aceptar una hipótesis como verdadera no es equivalente en todos los escenarios. Por ejemplo, las teorías que describen la decisión sobre los hechos como una abducción o una inferencia a la mejor explicación (Allen y PARDO, 2008: 229-231 y AmAYA, 2013: 14-18) ${ }^{55}$ advierten que la elección de la mejor hipótesis es sensible al contexto y a las explicaciones alternativas disponibles (AMAYA, 2010: $38^{56}$ y Allen y PARdo, 2008: 231-233).

a aquellos procedimientos abreviados en los cuales esa conformidad no incluye dicha aceptación. Por ejemplo, en el sistema estadounidense, no sería aplicable ante un plea de nolo contendere. A través de este, el imputado declara que no va a discutir el asunto de su culpabilidad o inocencia (KAMISAR, LAFAVE, IsRael, King y KerR, 2008: 1328).

55 Para Amaya, se trata de un proceso de maximización de la coherencia y, con ello, de selección de la explicación más coherente (2013: 4-5).

56 Como bien explica AmaYa, existen diferentes posiciones acerca de qué es aquello que varía con el contexto y, según Schaffer, aquello que cambia con el contexto son, justamente, las alternativas epistémicas — contrast set — que la hipótesis debe superar (2005: 115-129).

En un sentido similar, Grimaltos explica la posición de Lewis sobre el asunto, según la cual la consideración de posibilidades que impliquen la negación de nuestras creencias «hace que ya no pueda atribuirse el conocimiento que en el otro contexto, en el que no se las ha considerado, no tenía inconveniente en atribuirse» $y$, si bien la primera no acuerda con el segundo en que la existencia de conocimiento sea sensible al contexto, también asume que esas consideraciones prácticas pueden tener un efecto indirecto en aquel. En particular, que «la consideración de otras posibilidades, menos remotas, más probables y que en un primer momento he ignorado pueden producir el efecto del que habla Lewis", pero solo "si el hecho de considerar tal posibilidad hace que mi grado de certeza disminuya» (Grimaltos, 2009: 47-49). 
Entre los rasgos del contexto que son relevantes para fijar los estándares de justificación, Amaya ubica los rasgos dialécticos de la explicación y advierte que "[l]as prácticas de justificación tienen lugar en un contexto dialéctico que constriñe qué es lo que puede darse por sentado y qué es lo que, por el contrario, requiere ser justificado. El hecho de mencionar una hipótesis que tiene capacidad de derrotar a aquella que ha sido, provisionalmente, aceptada como justificada, obliga a incrementar el nivel de exigencia o, lo que es lo mismo, el umbral de justificación» (2010: 40-41). Como contrapartida, la expresa aceptación por parte del protagonista de los hechos de la descripción que de ellos hizo la fiscalía debilita los rasgos dialécticos del contexto en el que se discute la hipótesis acusatoria, lo cual permite disminuir, razonablemente, el grado de justificación exigible a la hora de tomar la decisión final.

Esto no significa que la falta de contradicción de la hipótesis acusatoria obligue a aceptarla, sino simplemente que, si la decisión sobre los hechos de un caso penal puede ser explicada como el proceso de selección de la hipótesis más plausible o de la explicación más coherente acerca de la evidencia disponible, la inexistencia de una hipótesis rival propuesta por el acusado modifica sensiblemente el contexto en el cual realizamos esa determinación final.

En otras palabras, si nos preocupara la circunstancia de que la condena resultante de esta clase de procesos pudiere gozar de un soporte en pruebas menor a aquel en el que se apoyan las resoluciones que emanan de un juicio ordinario - porque estas han satisfecho, por ejemplo, el estándar más allá de toda duda razonable-, lo cierto es que ello podría encontrar una explicación razonable en las especificidades del contexto epistémico que las rodea. Es decir, dados sus rasgos no dialécticos, es razonable y aceptable una disminución en el grado de exigencia de justificación de la decisión final.

Lo afirmado en este punto no significa que el caso nunca haya atravesado el análisis de hipótesis rivales. Ya vimos que el acuerdo, al estar sometido a un determinado estándar de probabilidad, puede haber involucrado el rechazo de hipótesis alternativas a la de la acusación en etapas procesales anteriores - esto es, en el análisis correspondiente a la examinación de la legitimidad de la propuesta de la fiscalía_ ${ }^{57}$. En cambio, la intención aquí es colocarnos frente al momento de decisión final del caso, que ya cuenta con el acuerdo completo y, así, con la expresa decisión del acusado de no controvertir la hipótesis acusatoria.

\subsection{Una manifestación de conformidad, en principio, epistémicamente confiable}

Se ha afirmado que una de las razones por las cuales una persona inocente podría decidir declararse culpable es "la conclusión de que es preferible una pena leve y

\footnotetext{
57 Véase supra nota 53.
} 
personalmente asumible, que el riesgo — aunque no sea elevado- de una pena más grave y difícil de asumir", razón por la cual resulta recomendable "combatir las acusaciones exageradas o infundadas, generadoras de miedos exagerados o infundados en el imputado" (Lascuraín SÁnCHEZ y Gascón, 2018: 15 y 21).

Ahora bien, sostuvimos antes que la legitimidad del plan unilateral declarado por la fiscalía, al proponer un acuerdo de culpabilidad, depende de la determinación de las condiciones bajo las cuales aquella puede demandar la realización de un juicio y la imposición, allí, de una pena mayor. Según vimos, la fiscalía puede ofrecer una recompensa por la renuncia al juicio — esto es, una disminución del castigo justo que es esperable allí-, pero no una penalidad por la elección de esa alternativa (véanse puntos 3.1 y 3.2 de este trabajo). Esto contribuye a disminuir el riesgo de que los acusados se vean psicológicamente compelidos a prestar conformidad en razón de la expectativa de imposición de una pena exagerada si optan por el juicio. La conciencia de que, en el eventual debate, solamente podrá imponerse la pena justa — según las características del hecho y las condiciones personales del acusado- o una inferior ${ }^{58}$, podría disminuir los incentivos para que los acusados inocentes se declaren culpables, pues removería buena parte del sustento al temor por un eventual castigo desproporcionado.

Algo similar sucedería a raíz de la adecuada revelación de la totalidad de la prueba relevante recolectada por la fiscalía ${ }^{59}$. Cuando el acusador es obligado a revelar la totalidad de la prueba de cargo y de descargo, reunida durante la investigación, los acusados inocentes son menos susceptibles a ser compelidos a confesar en razón del temor infundado a una condena errónea, ya que poseen información precisa acerca de la fortaleza del caso de la fiscalía y sobre el riesgo cierto de participar de un juicio ordinario (Petegorsky, 2018: 3613-3614) ${ }^{60}$.

58 La mayoría de las legislaciones procesales contiene reglas que prohíben a los jueces imponer sanciones superiores a aquellas solicitadas por los acusadores, de manera que el imputado, si no acepta el waiver reward, tendría garantizado que la pena en el eventual juicio no excederá, por decisión del tribunal, aquella determinada como justa en el trámite del acuerdo de culpabilidad.

59 La revelación de prueba de cargo suele ser considerada parte del derecho de defensa en los procedimientos de origen europeo-continental. Más precisamente, este derecho «no se difundió desde las jurisdicciones del common law hacia las del civil law. De hecho, fue adoptado más temprano por las jurisdicciones del civil law que por las del common law, no necesariamente porque las primeras estuvieran más orientadas al debido proceso que las últimas, sino probablemente porque el escenario institucional del sistema del civil law con su formal tratamiento de la etapa previa al juicio hizo más patente la necesidad de establecer y expandir este derecho una vez que le fue dado al acusado un rol más prominente en la resolución de los casos penales». Además, «las jurisdicciones del civil law han dado un mayor alcance al derecho que las del common law, en tanto las primeras dan a la defensa un temprano acceso a toda la investigación oficial que dirigen los funcionares públicos. Pero una vez más, este alcance más amplio no es resultado de una mayor orientación hacia el debido proceso en el sistema del civil law sino de la manera en que el asunto ha sido pensado dentro de un conjunto de prácticas institucionales preexistentes y una determinada concepción del proceso penal» (LANGer y RoACH, 2013: 8).

${ }^{60}$ En sus palabras, «by forcing disclosure of exculpatory evidence, a prosecutor cannot bluff her way to conviction by misrepresenting the strength of the government's case» (Petegorskr, 2013: 3613). Las 
La conformidad manifestada en estas condiciones resultaría, en principio, epistémicamente confiable ${ }^{61}$.

\section{CONCLUSIONES}

5.1. La observancia de determinadas condiciones mínimas de legitimidad moral en el marco de los acuerdos de culpabilidad, aunque no se funde en una concreta pretensión orientada a la averiguación de la verdad, repercute en las condiciones epistémicas en las cuales tomamos la decisión sobre la quaestio facti en ese contexto.

5.2. Los acuerdos de culpabilidad son procedimientos que permiten el dictado de una condena con prescindencia de la realización de un juicio y de la producción y discusión de la prueba en ese marco. Esto es posible, centralmente, en razón de la decisión del acusado de renunciar a su derecho a la celebración de ese juicio y a la corroboración de su culpabilidad, en dicho contexto, de acuerdo con el estándar probatorio normalmente aplicable — p. ej., más allá de una duda razonable-. Pese a ello, la circunstancia de que la fiscalía deba alcanzar un estándar probatorio bien determinado para proponer válidamente la celebración de un acuerdo —aquel equivalente al que resulte necesario para enviar un caso a juicio-, la inexistencia de hipótesis rivales a la acusatoria y una confesión que, en principio, es epistémicamente confiable, muestran que la decisión final sobre la quaestio facti en estos casos no viene asociada a un concepto de verdad consensual, sino que puede gozar de una genuina justificación epistémica, esto es, sobre la base de prueba y a la luz de una noción de verdad como correspondencia con la realidad.

5.3. Las conclusiones de este trabajo podrían objetarse observando que, al fin y al cabo, frente a la decisión definitiva de condena, que usualmente se halla sometida a un estándar probatorio muy exigente, terminamos conformándonos con un estándar menor, reservado para otro momento procesal, tal como es la apertura a juicio. Si nos preocupa la precisión fáctica de las decisiones resultantes del juicio penal, ¿por

implicancias de esa clase de bluff por parte de la fiscalía ha sido objeto de estudios y experimentaciones. Un interesante examen empírico sobre los efectos de esa clase de engaños - of being bluffed by the dealer - en la decisión de un acusado de aceptar un acuerdo de culpabilidad o confesar pueden verse en Wilford, 2014.

${ }^{61}$ Hablamos de una confesión confiable en principio porque la eliminación de las trial penalties es una condición necesaria, pero no suficiente, para garantizar la veracidad de esa declaración. Existen otros factores de riesgo - p. ej., malas prácticas policiales, tales como interrogatorios extensos, o bien encarcelamientos preventivos prolongados, entre otros-, que podrían incidir en esa decisión y cuyo análisis excede los limitados objetivos de este trabajo. Sin embargo, el objetivo de esta sección no es desarrollar exhaustivamente la totalidad de las condiciones que podrían incentivar confesiones falsas y, a nuestros fines, basta con asumir como cierta la premisa propuesta por LASCURAín SÁNCHEZ y GASCón, según la cual que el temor por una condena injusta y exagerada podría constituir uno de ellos. La determinación de la totalidad de las condiciones bajo las cuales una persona podría estar dispuesta a confesar falsamente demanda la realización de un análisis empírico que excede los alcances de este trabajo. 
qué no exigir que la decisión definitiva tras un acuerdo de culpabilidad se encuentre sometida al mismo estándar aplicable al juicio ordinario — certeza, más allá de una duda razonable, etcétera-?

En primer lugar, porque la condición de legitimidad de una condena dictada tras un acuerdo de culpabilidad no es, al menos principalmente, un determinado grado de comprobación de la culpabilidad del acusado, sino la decisión de éste de renunciar al juicio. Esto no quiere decir que el estándar más allá de toda duda razonable no pueda ser alcanzado en estos trámites, pero nuestra argumentación se encontró dirigida a demostrar un punto anterior, esto es, que la evaluación de la validez de esa renuncia no es independiente a la valoración de cierto grado de comprobación de la culpabilidad del acusado, de manera tal que, a pesar de la omisión del juicio, la decisión definitiva, a raíz de ese y otros factores, podría tener suficientes garantías epistémicas y no ser el producto de la confianza ciega en las afirmaciones de las partes. En otras palabras, ello no nos obliga, necesariamente, a concluir que la decisión definitiva tras el acuerdo - i.e., la condena- esté sometida a ese estándar de corroboración menor. Como ya vimos, la decisión que está sometida a ese estándar de corroboración menor es una anterior y diferente - la de llevar el caso a juicio-, con la cual se encuentra conectada, por razones morales, la evaluación de la legitimidad moral de la propuesta de la fiscalía.

\section{BIBLIOGRAFÍA}

AlLeN, Ronald J., 2010: «Versión plausible de culpabilidad sin otra alternativa plausible: Regla de decisión en el proceso penal» en Parcero, Juan A. Cruz y Laudan, Larry (comps.), Prueba y estándares de prueba en el derecho, UNAM, Instituto de Investigaciones Filosóficas.

AmaYA, Amalia, 2010: «Diez tesis acerca de la coherencia en el Derecho», Revista Discusiones, número X — La Coherencia en el Derecho-:. 21-64.

- 2013: "Coherence, evidence and legal proof", Legal Theory, 19, Cambridge University Press: 1-43.

Bergman, Marcelo, Fondevila, Gustavo y Langer, Máximo, 2017: ¿A quién y cómo se juzga en la Ciudad Autónoma de Buenos Aires? Una radiografía de la Justicia Nacional en lo Criminal y Correccional, Centro de Estudios Latinoamericanos sobre Inseguridad y Violencia, Universidad Nacional de Tres de Febrero.

Bertelotti, Mariano, 2009: «El control del mérito sustantivo de la investigación», en ANituA, Gabriel I. y Tedesco, Ignacio F. (comps.), La cultura penal - Homenaje al Profesor Edmundo S. Hendler, Buenos Aires: Editores del Puerto: 103-122.

Blank, Daniel P., 2000: «Plea Bargain Waivers Reconsidered: A Legal Pragmatist's Guide to Loss, Abandonment and Alienation", 68 Fordham L. Review: 2011-2095.

Bovino, Alberto, 2005: «Procedimiento abreviado y juicio por jurados», en MareR, Julio B. J. y Bovino, Alberto (comps.), El procedimiento abreviado, Buenos Aires: Editores del Puerto: 53-95.

Cafferata Nores, José I. y Hairabedián, Maximiliano, 2008: La prueba en el proceso penal, Buenos Aires: Lexis Nexis.

Córdoba, Gabriela, 2005: «El juicio abreviado en el Código Procesal Penal de la Nación Buenos Aires., en Maier, Julio B. J. y Bovino, Alberto (comps.), El procedimiento abreviado, Buenos Aires: Editores del Puerto: 229-250. 
DAmAšKa, Mirjan R., 1997: Evidence Law Adrift, Yale University Press, New Haven \& London. Citado por su traducción al castellano de Joan Picó I Junoy, El derecho probatorio a la deriva, Madrid: Marcial Pons, 2015.

— 2003: «Epistemology and legal regulation of proof” en Law, Probability and Risk, Oxford University Press.

Dei Vecchi, Diego, 2016: «La prueba judicial como conocimiento: una caracterización poco persuasiva”, en Ferrer Beltrán, Jordi y Vázquez, Carmen (coeds.), Debatiendo con Taruffo, Madrid: Marcial Pons.

Dias, Leandro, 2015: «Los acuerdos en Derecho penal en Karlsruhe y Estrasburgo: análisis de las recientes sentencias del Tribunal Constitucional Federal Alemán y del Tribunal Europeo de Derechos Humanos Buenos Aires», en Pensar en Derecho, nro. 6.

Díaz Cantón, Fernando, 2005: «Juicio abreviado vs. estado de derecho Buenos Aires», en Maier, Julio B. J. y Bovino, Alberto (comps.), El procedimiento abreviado, Buenos Aires, Editores del Puerto, pp. 251-276.

DíAz, E. Matías, 2017: Sobre la verdad y la protección de la inocencia en el proceso penal, Buenos Aires: Ad Hoc.

Douglass, John G., 2001: «Fatal Attraction? The Uneasy Courtship of Brady and Plea Bargaining», 50 Emory L.J: 437-5118.

Duff, A., Farmer, L., Marshall, S. y Tadros, V., 2007: The Trial on Trial: Volume 3. Towards a Normative Theory of Criminal Law, Oxford - Portland, Hart Publishing.

Farrell, Martin y Spector, Horacio, 1992: "Dos tesis sobre amenazas y ofertas", en Cornblit, Oscar (comp.), Libertad y Mercado, Buenos Aires: Macchi.

Ferrajoli, Luigi, 1989: Diritto e ragione. Teoria del garantismo penale, Roma, Ed. Laterza \& Figli. Citado por la traducción al castellano de Andrés IbÁNÉEz y otros, Derecho y Razón. Teoría del garantismo penal, novena edición, Madrid: Ed. Trotta, 2009.

Ferrer Beltrán, Jordi, 2005: Prueba y verdad en el derecho, Madrid: Marcial Pons.

- 2007: La valoración racional de la prueba, Marcial Pons, Madrid

- 2010: «El contexto de la decisión sobre los hechos probados en el derecho», en Parcero, Juan A. Cruz y Laudan, Larry (comps.), Prueba y estándares de prueba en el derecho, UNAM, Instituto de Investigaciones Filosóficas.

- 2018: «Prolegómenos para una teoría sobre los estándares de prueba. El test case de la responsabilidad del Estado por prisión preventiva errónea», en Papayannis, Diego M. y Pereira Fredes, Esteban (eds.), Filosofia del derecho privado, Madrid, Marcial Pons.

Foucault, Michel, 2014: Obrar mal, decir la verdad, Buenos Aires: Siglo XXI.

Gascón Abellán, Marina, 2010: Los hechos en el derecho, Madrid: Marcial Pons.

González Lagier, Daniel, «¿Es posible formular un estándar de prueba preciso y objetivo? Algunas dudas desde un enfoque argumentativo de la prueba», inédito.

- 2003: "Hechos y argumentos (Racionalidad epistemológica y prueba de los hechos en el proceso penal) (II) ", en Jueces para la democracia, número 47.

Grande, Elisabetta, 2008: «Dances of Criminal Justice: Thoughts on Systemic Differences and the Search for the Truth", en Jackson, John, Langer, Máximo y Tillers, Peter, Crime, Procedure and Evidence in a Comparative and International Context - Essays in Honour of Professor Mirjan Damaška, Oxford: Hart Publishing.

Grimaltos, Tobies, 2009, «Creencia, aceptación y conocimiento» Episteme NS, vol. 29, nro. 1,: 35-50. Guzmán, Nicolás, 2005, "La verdad y el procedimiento abreviado», en MAIER, Julio B. J. y Bovino, Alberto (comps.), El procedimiento abreviado, Buenos Aires: Editores del Puerto.

HaAck, Susan, 1978, Prhilosophy of logics, Cambridge: Cambridge University Press.

— 2013: "El probabilismo jurídico: una disensión epistemológica”, en VÁzQuez, Carmen (ed.), Estándares de prueba y prueba cientifica, Madrid: Marcial Pons, 2013:. 65-98.

- 2014: Evidence matters: science, proof, and truth in the law, New York: Cambridge University Press.

Kagan, Robert A., 2001, Adversarial legalism: the American way of law, Harvard University Press. 
Kamisar, Yale, LaFave, Wayne R., Israel, Jerold H., King, Nancy J. y Kerr, Orin S., 2008: Advanced Criminal Procedure, EEUU: Thompson/West.

KipNIs, Kenneth, 1976: «Criminal Justice and the Negotiated Plea”, Ethics, 86: 93-106.

Langbein, John H., 1978: "Torture and Plea Barganining», The University of Chicago Law Review, vol. 46, pp. 3 y siguientes. Citado por su traducción al castellano: «Tortura y plea bargaining», en Maier, Julio B. J. y Bovino, Alberto (comps.), El procedimiento abreviado, Buenos Aires: Editores del Puerto, 2005: 3-29.

Langer, Máximo, 2004: «From Legal Transplants to Legal Translations: The Globalization of Plea Bargaining and the Americanization Thesis in Criminal Procedure», Harvard International Law Journal, 2004, vol. 45. Citado por su traducción al castellano de Lucas TASSARA: «De los trasplantes a las traducciones legales: la globalización del plea bargaining y la tesis de la 'americanización' en el proceso penal», Revista Discusiones, nro. 21, 2018: 25-134.

- 2005: «La dicotomía acusatorio-inquisitivo y la importación de mecanismos procesales de la tradición jurídica anglosajona. Algunas reflexiones a partir del procedimiento abreviado" en MaIER, Julio B. J. y Bovino, Alberto (comps.), El procedimiento abreviado, Buenos Aires: Editores del Puerto.

- 2006: «Rethinking Plea Bargaining: The Practice and Reform of Prosecutorial Adjudication in American Criminal Procedure», 33 AM. J. CRIM. L. 223, 248. Traducido al castellano por Agustín Varela y E. Matías Díaz, en «Repensando el Plea Bargaining: La Práctica y la Reforma del Juzgamiento por los Fiscales en el Proceso Penal Estadounidense", en Langer, Máximo, ¿¿Para qué sirve un modelo procesal? Ensayos sobre los sistemas acusatorio e inquisitivo, Madrid: Marcial Pons, en prensa.

- 2019: «Plea bargaining, trial-avoiding conviction mechanisms, and the global adminitratization of criminal convictions", Annu. Rev. Criminol., DOI: 10.1146/annurev-criminol-032317-092255.

LANGer, Máximo y Roach, Kent, 2013: "Derechos en el procedimiento penal: un estudio sobre la convergencia de los sistemas y el derecho del imputado a acceder a los elementos de prueba", en Mark Tushnet, Thomas Fleiner \& Cheryl Saunders, HANDBOOK OF CONSTITUTIONAL LAW 273, Routledge.

Lascuraín SÁNChez, Juan Antonio e Inchausti, Facundo Gastón, 2018: «¿Por qué se conforman los inocentes? ", InDret - Revista para el análisis del Derecho, Barcelona.

Laudan, Larry, 2006: Truth, Error and Criminal Law, Cambridge University Press. Citado por su traducción al castellano por Carmen Vázquez y Édgar Aguilera, Verdad, error y proceso penal, Madrid: Marcial Pons, 2013.

Limardo, Alan, 2018: "Control judicial de la acusación: Alcance y operatividad respecto del mérito de la prueba», en Rúa, Gonzalo (dir.), Limardo, Alan y Rovatti, Pablo (coords.), Estudios sobre el sistema penal adversarial, Buenos Aires: Ed. Didot: 95-126.

LIPPKE, Richard L., 2011: The Ethics of Plea Bargaining, Oxford: Oxford University Press.

MaffeI, Stefano, 2004: «Negotiations 'on Evidence' and Negotiations 'on sentence' - Adversarial Experiments in Italian Criminal Procedure», Journal of International Criminal Justice 2.

Magariños, H. Mario, 1999: «El 'juicio previo' de la Constitución Nacional y el 'juicio abreviado' Ley 24825", en Cuadernos de Doctrina y Jurisprudencia Penal, Ad Hoc, año V. nro. 9-B.

Maier, Julio B. J., 2004: Derecho Procesal Penal, t. I. Fundamentos, Buenos Aires: Editores del Puerto. - 2011: Derecho procesal penal, T. III, Buenos Aires: Editores del Puerto.

Pastor, Daniel, 2009: El plazo razonable en el proceso del Estado de Derecho, Buenos Aires: Ad Hoc.

Petegorsky, Michael Nasser, 2013: «Plea Bargaining in the Dark: The Duty to Disclose Exculpatory Brady Evidence during Plea Bargaining», 81 Fordham L. Review: 3599-3650.

Redicich, Allison D. y Shteynberg, Reveka V., 2016: «To plead or Not to Plead: A Comparison of Juvenile and Adult True and False Plea Decisions», Law and Human Behavior, vol. 40, nro. 6: 611625.

SAncinetTi, Marcelo A., 2010: «Avenimiento y mediación: ¿̨la pena como 'objeto de negocios jurídicos'? ", en elDial.com, Doctrina, DC138 F.

Schaffer, Jonathan, 2005: «What shifts? Thresholds, Standards, or Alternatives? », en Preyer, Gerhard \& Peter, Georg (eds.) Contextualism in Philosophy: Knowledge, Meaning and Truth. 
TARuffo, M., 1992: La prova dei fatti giuridici, Milano: Giuffré Editore. Citado por la versión castellana de Ferrer Beltrán, Jordi, La prueba de los hechos, Trotta, Madrid, 2011.

— 2008: La prueba, Madrid: Marcial Pons.

- 2010: «Conocimiento científico y estándares de la prueba judicial», en Parcero, Juan A. Cruz y Laudan, Larry (comps.), Prueba y estándares de prueba en el derecho, UNAM, Instituto de Investigaciones Filosóficas.

Timmons, Mark, 2002: Moral Theory: An introduction, Oxford: Rowman and Littlefield.

VeLEDA, Diana, 2019: «Delimitación del control judicial en el avenimiento. Su relación con el carácter acusatorio del proceso penal de la CABA y con el mejoramiento de las condiciones de legitimidad de los acuerdos", en Díaz, E. Matías, Perel, Martín (dirs.) y Veleda, Diana (coord.), Aspectos relevantes del juicio en el procedimiento penal de la CABA, Buenos Aires: Ad-Hoc.

Weigend, Thomas, 2008: «The Decay of the Inquisitorial Ideal: Plea Barganing Invades German Criminal Procedure», en Jackson, John, Langer, Máximo y Tillers, Peter (eds.), Crime, Procedure and Evidence in a Comparative and International Context - Essays in Honour of Professor Mirjan Damaška, Hart Publishing.

Wertheimer, Alan, 1979: «The prosecutor and the gunman», Ethics, volume 89, nro. 3, 269-279.

Wilford, Miko M., 2014: «Bluffed by the dealer: Distinguishing false pleas from false confessions», Graduate Theses and Dissertations, Iowa State University, 13877. 